Asian Journal of Computer Science and Technology ISSN: 2249-0701 Vol.7 No.2, 2018, pp.57-61

(C) The Research Publication, www.trp.org.in

\title{
E-Era of Jurisdiction:Empowering Traditional Courts Using Various Artificial Intelligence Tools
}

\author{
Balam Singh Dafauti \\ School of Computer Science \& IT, Uttarakhand Open University, Haldwani. Uttarkhand, India \\ E-Mail: balamdafouti@gmail.com
}

\begin{abstract}
In Indian scenario, we are still in the transformation phase from manual to electronic data processing. We are in balanced combination of simple, moral, responsive and transparent governance and IT tools and techniques. However a lot of scope is still there to do more and to imply IT in various governmental departments and domains. In the same sequence we can use artificial intelligence along with cloud computing to improve Indian Judicial system. Or we can say that the concept of e-courts can be enhanced by implying AI tools and techniques. The judiciary is in the early stages of a transformation in which AI (Artificial Intelligence) technology will help to make the judicial process faster, cheaper, and more predictable without compromising the integrity of judges' discretionary reasoning. In this paper I have proposed a solution where judicial system with AI contributes to a process that encompasses such a wide range of knowledge, judgment, and experience. It have two more practical goals: producing tools to support judicial activities, including programs for intelligent document assembly, case retrieval, and support for discretionary decision-making; and developing new analytical tools for understanding and modeling the judicial process.
\end{abstract}

Keywords: Artificial Intelligence, Cloud Computing, ecourts, intelligent document assembly, case retrieval, analytical tools, and case based reasoning, formal models of dialectics, argumentation and negotiation

\section{INTRODUCTION OF ARTIFICIAL INTELLIGENCE}

Artificial intelligence (AI) is the intelligence of machines and the branch of computer science that aims to create it. AI textbooks define the field as "the study and design of intelligent agents" where an intelligent agent is a system that perceives its environment and takes actions that maximize its chances of success. John McCarthy, who coined the term in 1955, defines it as "the science and engineering of making intelligent machines."

AI research is highly technical and specialized, deeply divided into subfields that often fail to communicate with each other. Some of the division is due to social and cultural factors: subfields have grown up around particular institutions and the work of individual researchers. AI research is also divided by several technical issues. The central problems of AI include such traits as reasoning, knowledge, planning, learning, communication, perception and the ability to move and manipulate objects. General intelligence (or "strong AI") is still among the field's long term goals.

Artificial intelligence has been used in a wide range of fields including medical diagnosis, stock trading, robot control, law, scientific discovery and toys. "Many thousands of AI applications are deeply embedded in the infrastructure of every industry." the late 90 s and early 21 st century, AI technology became widely used as elements of larger systems, but the field is rarely credited for these successes.

As Artificial Intelligence (AI) technology develops, the creation of computers that can autonomously reason with the law to determine legal solutions is slowly becoming a reality. Expert systems will one day be able to predict the outcome of litigation with a good degree of accuracy. An important attribute of expert systems is their ability to explain why a particular analysis or recommendation was produced. The process usually involves the assignation of numerical "weights" in relation to case facts. These facts are then computationally compared to similar cases in the expert system's knowledge base and an outcome based on the assigned values/similarities is then generated. Therefore, the possibility exists that AI will result in expert systems that could help judges produce an acceptable level of fairness without resorting to a strict model of fixed sentencing. The expert system would be normative rather than predictive, providing guidance based on complex modeling that considers the attributes of the crime, mitigating and aggravating circumstances, and the individual characteristics of the defendant.

\section{II.VARIOUS E GOVERNANCE INITIATIVES IN INDIA}

In the democratic country like India, Government is a form of public organization, set up by the collaboration with the society; with an objective of fulfilling society's developmental needs.Here, government legitimacy and transparency are the central criteria along with the organizational development for the smooth functioning of the government. The model of e-governance is based on the efficient delivery of information and services to the nation through different mode of managing the information. Applying the combination of information and communication technology results in SMART (Simple, 
Moral, Accountable, Responsive, Transparent) governance.This interactive tool enables the active citizen participation through wide services such as informing, representing, encouraging and consulting various activities.

Recognizing the increasing importance of electronics, the Government of India established the Department of Electronics in 1970. The subsequent establishment of the National Informatics Centre (NIC) in 1977 was the first major step towards e-Governance in India as it brought 'information' and its communication in focus. In the early 1980s, use of computers was confined to very few organizations. The advent of personal computers brought the storage, retrieval and processing capacities of computers to Government offices. By the late 1980s, a large number of government officers had computers but they were mostly used for 'word processing'. Gradually, with the introduction of better software, computers were put to other uses like managing databases and processing information. Advances in communications technology further improved the versatility and reach of computers, and many Government departments started using ICT for a number of applications like tracking movement of papers and files, monitoring of development programmes, processing of employees' pay rolls, generation of reports etc.

Backus (2003) defines the concept of e-governance as an interactive tool that enables G-C (government-customer), GB (government -business) and G-G (governmentgovernment) interactions to simplify and improve governments and business aspects of governance.

Similarly the former president of India, Dr. A.P.J. Abdul kalam, visualized the term of e-governance as "transparent smart Governance with seamless access, secure and authentic flow of information crossing the interdepartmental barriers and providing a fair and unbiased service to the citizen".

With National e-governance plan (NeGP) working from June 2006, various Indian states have got advantage of ICT based solutions of public administration problems. Either it is the domain of land record registration or the problem of issuing driving license or domicile certificate, every thing has become online these days.

Both government departments and the citizen of India are getting benefits with various e-governance projects.

From e-District to e-Court, from e-banking to e-hospital every service sector has become computerized these days. With the help of various hardware, softwares, networks, databases and data warehouses miraculous things have become possible.

\section{CONCEPT OF E-COURTS IN INDIA}

Government of India approved the e-courts project in February 2007 and the first phase is already under implementation. National Informatics Centre (NIC), which is the implementing agency for this project, has reported that hitherto, laptops to 12155 judges across the country have been provided and around 13000 laser printers are getting delivered for those laptops. Three months' training on the usage of computers has already begun and 1210 faculty members are training so far 8700 judicial officers and around 32000 court staff. This training is going on at majority of the District Courts and in some of the Taluka/Tehsil Courts. The High Courts have constituted Project Monitoring Committees to oversee the project activities in the District/Taluka Courts under their jurisdiction. Many High Courts have also constituted Committees for getting site preparation executed with the help of State Public Works Department. For around 13000 judges E-mail/Internet facility is being provided through Bharat Sanchar Nigam Limited.It would inter link all the courts across the country and help the litigants to have access to authorized documents.

The entire project is scheduled to be implemented by February 2009 across the country including in the districts of Orissa E-court project is meant to facilitate integration of all courts, sharing of data among courts and creation of a National Judicial Grid. The e-court mission mode project will use standard software for all district and subordinate court across the country.

Delivering the inaugural address at the State-level launch of the e-court project at the District Court Complex, Mr. P.K. Balasubramanian, Chairman, e-committee of the Supreme Court said that cooperation from the State government was required to maintain the e-court system. He also told that the e-committee also proposed to create a data bank by making judgments available online and to archive the records so that record rooms can be utilized better.

\section{A. Services}

1. List of 8 services is to be provided under this project

2. Online availability of judgments, cause list etc.

3. e-filing of cases

4. Notices through emails provided clients email ID is available

\section{B. Status}

1. E-Court monitoring Committee constituted to oversee implementation - December 2004.

2. National Policy and action plan for implementation of ICT in Indian Judiciary formulated by e-Committee 700 courts in Metro cities covered.

3. 900 Courts in capital cities barring North- East, Ahmadabad, and Patna covered.

4. Cabinet has approved the scheme for covering 2100 court complexes: approved Rs. 442 crore to be completed in 2 years.

5. NIC to implement project under overall guidance of eCommittee. 


\section{IV.A PROPOSED FRAMEWORK OF E-COURT THE HELP OF AI}

The Indian judiciary comprises of nearly 15,000 courts situated in approximately 2,500 court complexes throughout the country. In the Indian Judiciary, effort for computerization of some of its processes has been going on since 1990. From 2001-03, 700 city courts in four metros were computerized and during 2003-04, computerization of another 900 courts were undertaken.

A need was felt to make the programme of ICT enablement of the Indian Judiciary mission-critical. Under NeGP as a Mission Mode Project, it is proposed to implement ICT in Indian judiciary in three phases over a period of five years. The project scope is to develop, deliver, install and implement automated decision making and decision support system in 700 courts of Delhi, Bombay, Kolkata \& Chennai; 900 courts in the 29 capital city courts of states and UTs and 13000 district and subordinate courts. The objectives of the project are:

1. To help judicial administration of the courts in streamlining their day-to-day activities

2. To assist judicial administration in reducing the pendency of cases

3. To provide transparency of information to the litigants

4. To provide access to legal and judicial databases to the judges.

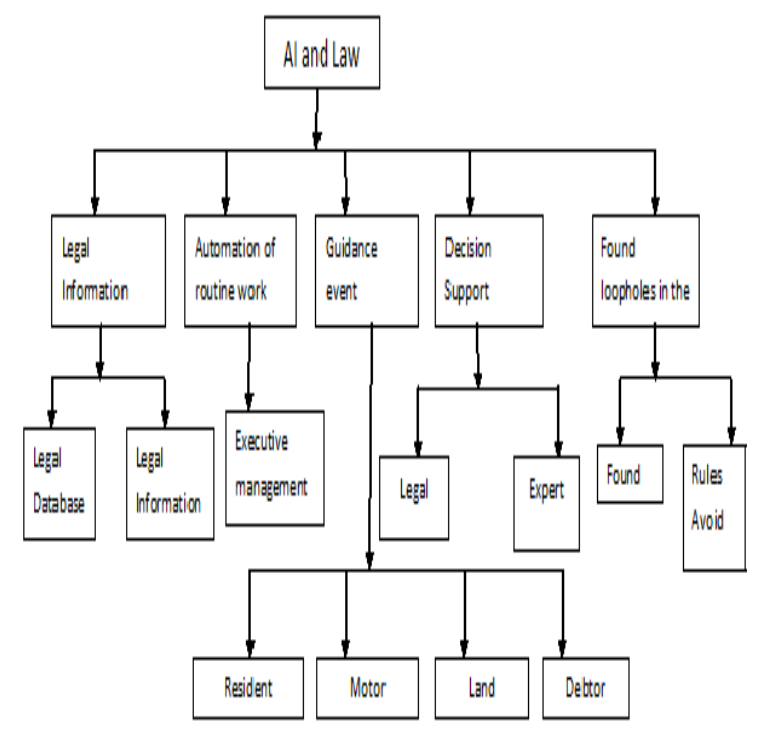

Fig. 1 System diagram of Artificial Intelligence and law

While computers have long been a fixture in the legal profession, they have mainly been relegated to back office tasks, such as billing, word processing, and other basic administrative duties. As Artificial Intelligence (AI) technology develops, the creation of computers that can autonomously reason with the law to determine legal solutions is slowly becoming a reality.
Expert systems will one day be able to predict the outcome of litigation with a good degree of accuracy. An important attribute of expert systems are their ability to explain why a particular analysis or recommendation was produced. The process usually involves the assignation of numerical "weights" in relation to case facts. These facts are then computationally compared to similar cases in the expert system's knowledge base and an outcome based on the assigned values/similarities is then generated. Therefore, the possibility exists that AI will result in expert systems that could help judges produce an acceptable level of fairness without resorting to a strict model of fixed sentencing. The expert system would be normative rather than predictive, providing guidance based on complex modeling that considers the attributes of the crime, mitigating and aggravating circumstances, and the individual characteristics of the defendant.

At present, expert systems of this complexity are not in widespread use. Some simple software is available that provides legal professionals with the ability to draft complex legal documents. The software works on rule based principles, which guide the lawyer through a question-andanswer session until the document is complete. These software programs typically support each question with expert legal and strategic analysis, practice tips and model language.

The two main parts of AI based legal information system are:

1. The main legal database

2. Case based reasoning

\section{A. The main legal database}

The first stage in the methodology is the critical Needs Assessment. To provide a context, we set forth here a broad overview of the major database design and end user access considerations. There are four overriding and interrelated database design and end user access considerations that must be addressed and resolved during the Needs Assessment stage. The first is the ultimate size of the database in terms of number of documents. The second is the nature and scope of the finding tools that are used to identify potentially relevant documents in the database. The third is the format for the documents retrieved in response to a search query - that is, in full-text format, in image format, or in both formats. And the fourth and final overriding consideration is the requirements for distributing the database over the World Wide Web or on local media (such as CD-ROMs), or both.

The added-value features and their associated converted documents (in either or both image format or full-text format) need to be incorporated into the database on a timely and accurate basis. This could be another responsibility of central repository personnel, or the task could be outsourced or performed by a private sector vendor distributing the database to end users. Whatever 
organization is responsible for creating, maintaining and updating the database, technology will play a major role in implementation. An important issue in determining the appropriate technology is the requirements for security, reliability, and performance.

The institutional capacity of the organization that is responsible for creating, maintaining and updating the database on a timely, accurate and comprehensive basis, and for operating and managing the technology, needs to be evaluated during the Needs Assessment. This part of the assessment will result in a suggested training and skills transfer program.

This same organization that maintains and updates the database will most likely also distribute the database, with the alternatives for distribution being online (e.g., as webbased for distribution over the World Wide Web) or offline (e.g., on CD-ROMs). For online distribution, the main issues are reliability and performance. One critical performance issue here involves the bandwidth requirements if image formatted documents are contained in the database. For offline distribution, the main issues are (a) the number of required distribution media, which in turn is a function of the size of the database; and (b) the frequency required for distributing the current version of the database. Again these distribution issues need to be addressed and resolved during the Needs Assessment. A conceptual design of required legal database is given as below:-

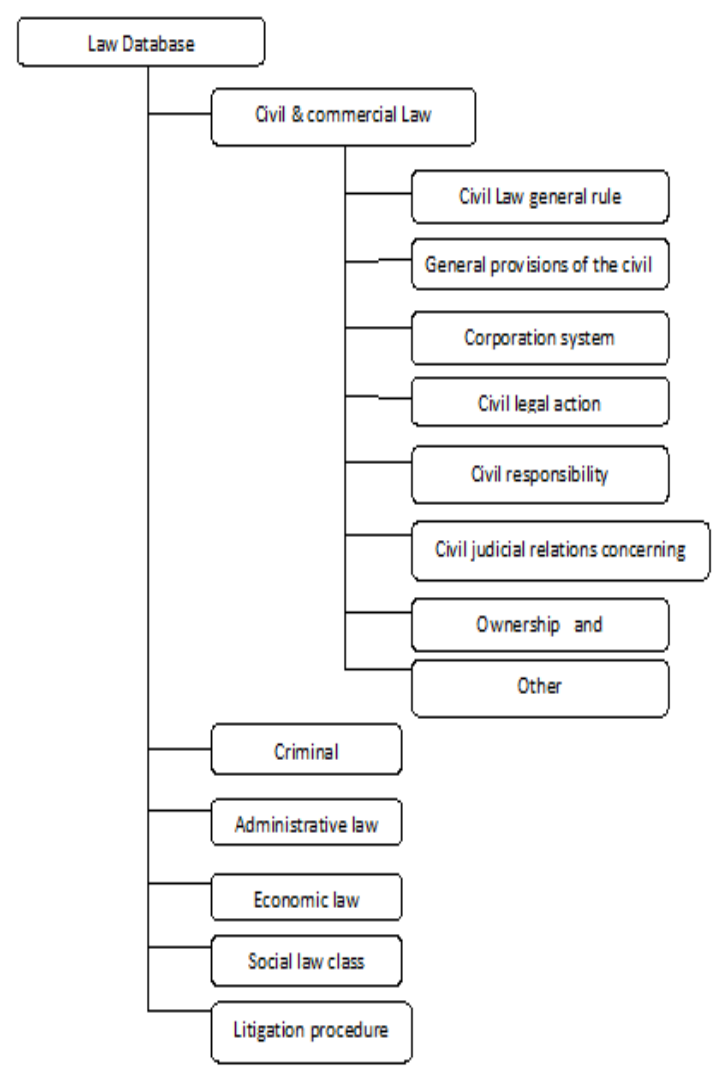

Fig. 2 Conceptual Design of database

\section{B. Case-based Reasoning Process}

Case-based reasoning (CBR), broadly construed, is the process of solving new problems based on the solutions of similar past problems. An auto mechanic who fixes an engine by recalling another car that exhibited similar symptoms is using case-based reasoning. A lawyer who advocates a particular outcome in a trial based on legal precedents or a judge who creates case law is using casebased reasoning. So, too, an engineer copying working elements of nature (practicing biomimicry), is treating nature as a database of solutions to problems. Case-based reasoning is a prominent kind of analogy making.

It has been argued that case-based reasoning is not only a powerful method for computer reasoning, but also a pervasive behavior in everyday human problem solving; or, more radically, that all reasoning is based on past cases personally experienced. This view is related to prototype theory, which is most deeply explored in cognitive science. In case-based reasoning (CBR) systems expertise is embodied in a library of past cases, rather than being encoded in classical rules. Each case typically contains a description of the problem, plus a solution and/or the outcome. The knowledge and reasoning process used by an expert to solve the problem is not recorded, but is implicit in the solution.

To solve a current problem: the problem is matched against the cases in the case base, and similar cases are retrieved. The retrieved cases are used to suggest a solution which is reused and tested for success. If necessary, the solution is then revised. Finally the current problem and the final solution are retained as part of a new case. Case-based reasoning has been formalized for purposes of computer reasoning as a four-step process:

1. Retrieve: Given a target problem, retrieve from memory cases relevant to solving it. A case consists of a problem, its solution, and, typically, annotations about how the solution was derived. For example, suppose Fred wants to prepare blueberry pancakes. Being a novice cook, the most relevant experience he can recall is one in which he successfully made plain pancakes. The procedure he followed for making the plain pancakes, together with justifications for decisions made along the way, constitutes Fred's retrieved case.

2. Reuse: Map the solution from the previous case to the target problem. This may involve adapting the solution as needed to fit the new situation. In the pancake example, Fred must adapt his retrieved solution to include the addition of blueberries.

3. Revise: Having mapped the previous solution to the target situation, test the new solution in the real world (or a simulation) and, if necessary, revise. Suppose Fred adapted his pancake solution by adding blueberries to the batter. After mixing, he discovers that 
the batter has turned blue - an undesired effect. This suggests the following revision: delay the addition of blueberries until after the batter has been ladled into the pan.

4. Retain: After the solution has been successfully adapted to the target problem, store the resulting experience as a new case in memory. Fred, accordingly, records his new-found procedure for making blueberry pancakes, thereby enriching his set of stored experiences, and better preparing him for future pancake-making demands.

\section{ADVANTAGES OF INTEGRATING AI TECHNIQUES AND E-COURT CONCEPTS}

The Indian judiciary comprises of nearly 15,000 courts situated in approximately 2,500 court complexes throughout the country. Under the e-Courts MMP, it is proposed to implement ICT in Indian judiciary in 3 phases over a period of 5 years. The MMP aims to develop, deliver, install, and implement automated decision-making and decision support systems in 700 courts across Delhi, Bombay, Kolkata and Chennai; 900 courts across 29 State/ Union Territory capitals; and 13,000 district and subordinate courts across the Nation.

The objectives of the project are:

1. To help judicial administration in streamlining their day-to-day activities

2. To assist judicial administration in reducing the pendency of cases

3. To provide transparency of information to the litigants

4. To provide judges with easy access to legal and judicial databases

\section{CONCLUSION}

As we can see IT tools and techniques have influenced many aspects of our lives. New inventions of IT like artificial intelligence, cloud computing, neural networks and expert systems have benefited our government and business organizations a lot. In the same sequence use of AI tools and techniques to enhance the idea of e-court, to provide a better judicial environment to the Indian people and also to support judges in their heavy task of analyzing the case and decision making.

It is a concept given by us to make a decision support system for judges based on legal database and case based reasoning. A complete system diagram has been introduced by us for using AI in the field of law.

Building a good legal database based on the application of AI, will help to improve efficiency and judicial impartiality. Further control of artificial intelligence and legal content of the main research topics, such as legal information, knowledge engineering and other are the main areas of research work.

\section{REFERENCES}

[1] Simon Chlton, "Legal Diagnostics", Computers and Law, Vol. 25, pp. 13-15, 1980.

[2] Blyan Niblett, "Expert Systems for Lawyers", Computers and Law. Vol. 29, No. 2, 1981.

[3] Buchanan and Headrick, "Some Speculation About Artificial Intelligence and Legal Reasoning", Stanford Law Review. Vol. 23, pp. 40-62, 1970.

[4] J. Kraus and P.E. Quinn, "Human artificial insemination: some social and legal issues", Med J Aust., Vol. 1, No. 19, pp. 710-3, 1977.

[5] A. Heitlinger, "Current medical, legal and demographic perspectives on artificial reproduction in Czechoslovakia", Am J Public Health, Vol. 79, No. 1, pp. 57-61, 1989.

[6] R.Schank and R. R.Abelson, "Goals and Understanding [M]", Erlbranum: Eksevier Science, http://en.wikipedia.org/wiki/Casebased_reasoning, 1977. 